\title{
A moving video window or mask yoked to eye movements: A system to permit free ocular scanning within delimited areas of the visual field
}

\author{
NORMAN C. NETTLETON, ROBERT G. WOOD, JOHN L. BRADSHAW, \\ C. DAVID L. THOMAS, and KEVIN B. DONAHOO \\ Monash University, Clayton, Victoria, Australia
}

\begin{abstract}
A system is described for generating a video window or mask that is yoked to a subject's eye movements and that can be used to mask off either the left or the right visual field, while still permitting prolonged examination of simple or complex visual stimuli. It can also be used to simulate various visual field defects or scotomata and to ensure that subjects maintain fixation during extended stimulus presentations. Circuitry is provided, and two additional options are suggested.
\end{abstract}

In his critique of the then current approaches to perception and cognition, Neisser (1976) quite properly expressed reservations about the "ecological validity" of tachistoscopic procedures. When stim ulation of discrete retinal areas or parts of the visual field is required, or an input free of contributions from fixational eye movements by a subject, tachistoscopic presentation has hitherto been almost obligatory. Because fixational eye movements can usually be initiated in around $175 \mathrm{msec}$ (Rayner, 1978; for review, see Young, 1982) and because most of the visual information necessary for reading can be obtained within the initial 50 -msec period of a fixation (Rayner, Inhoff, Morrison, Slowiaczek, \& Bertera, 1981), exposure durations are usually kept at or below $150 \mathrm{msec}$. There are, however, a number of applications in which it would be desirable to employ longer presentations. These applications include the central or peripheral presentation of complex figures of high information content, studies of visual selective attention with simultaneous exposures to the peripheral and central fields (Mackworth, 1965), laterality experiments in which the left or the right visual field is to be stimulated with patterned or verbal material (for review, see Bradshaw \& Nettleton, 1983, chap. 6), and clinical applications in which

This work was supported by an award to two of the authors (J.L.B. and N.C.N,) by the Australian Research Grants Committee. This support is gratefully acknowledged. We also wish to acknowledge the help and advice received from Ed Howell, Geoff Mead, Greg Nathan, and Richard Newman. Kevin Donahoo, who did the initial developmental work, is now with Kenelec Australia, and David Thomas, who worked on the project for 13 months, is now at the University of Melbourne Dental School. Please address reprint requests to Norman C. Nettleton, Faculty of Education, Monash University, Clayton, Victoria 3168, Australia. slow readers or developmental dyslexics are under investigation (e.g., Zangwill \& Blakemore, 1972; for review, see Bradshaw \& Nettleton, 1983, chap. 13).

\section{GETTING AWAY FROM THE TACHISTOSCOPE}

Myers and Sperry (1982) suggested a simple technique for lateralizing visual input. Subjects whose head positions are controlled by a biteboard are required to turn their eyes fully to the left or the right to view the stimulus material. Although it allows prolonged viewing, since the subjects are physically unable to deviate their eyes further, such a technique introduces its own problems, notably the possibility that such laterally directed gaze may differentially "switch in" one or the other hemisphere by asymmetric attentional activation (Kinsbourne, 1975; but also see Bradshaw \& Nettleton, 1983, chap. 7). Indeed, it probably has no more "ecological validity" (Neisser, 1976) than tachistoscopic techniques.

Hitherto, three major approaches have sought to make visual stimulation either contingent upon or independent of eye movements; each approach has certain problems and limitations. In the stabilized retinal image technique (Ditchburn \& Ginsborg, 1952; Riggs, Ratliff, Cornsweet, \& Cornsweet, 1953), an optical system, incorporating a closely fitting corneal contact lens that bears a mirror, places an image onto a discrete and fixed retinal locus, irrespective of eyemovements. Ideal for studying the time course of perceptual processes in the absence of saccades, drifts, or tremor, the technique is somewhat uncomfortable for the subject, is unsuitable for stimulus presentations exceeding a few seconds (because of image fading), and does not allow for 
free scanning of the stimulus by exploratory eye movements. More recently, Zaidel (1975) developed a modified version of this system whereby prolonged exposure with free ocular scanning is possible, since it is the image of the occluder that is stabilized, rather than that of the stimulus. Zaidel (1976, 1978a, 1978b) has successfully used this system in a number of studies with commissurotomy patients, but it still retains all the drawbacks associated with fitting and wearing contact lenses, particularly lens slippage.

A second approach, also dependent upon contact lenses, is that of Dimond, Bures, Farrington, and Brouwers (1975) and Dimond and Farrington (1977). In effect, their lenses functioned as visual hemifield occluders, being opaque except for a slit. Independently, in our own laboratory, we tried to develop an almost identical system, but found that optical diffraction around the edge of the slit made its worth somewhat suspect. In any case, their lenses are no less tedious to fit, and no less uncomfortable, than are those used for stabilized retinal images. Indeed, in both cases, individually fashioned lenses must be constructed for each subject.

Finally, McConkie, Zola, Wolverton, and Burns (1978), Rayner (1975), and Reder (1973) developed sophisticated computer-based systems with which subjects' eye movements are monitored as they read text displayed on a cathode-ray tube (CRT) and changes in the text are made contingent upon the eye movements. A number of successful studies have been carried out using these computer-based systems (for review, see McConkie et al., 1978, and Rayner, 1979; also see Pollatsek, Bolozky, Well, \& Rayner, 1981, Rayner et al., 1981, Rayner, Well, \& Pollatsek, 1980, and Salthouse, Ellis, Diener, \& Somberg, 1981). Such systems are, of course, in some respects the most flexible possible, since the image can be stabilized relative to the retina, if desired, or scanned within whatever limits are set by the experimenter. They do however depend on the availability of a fairly powerful computer and a considerable amount of sophisticated software, and the stimulus material is limited to whatever can be generated on the CRT.

The system described below uses a standard video monitor on which a wide range of material can be displayed to whatever area of the subject's visual field the experimenter chooses. It can be used to mask off either the left or the right visual field, to simulate tunnel vision, or, conversely, to simulate a central or peripheral scotoma. It can also be used to control eye movements during tachistoscopic presentations longer than the usual $150 \mathrm{msec}$ by masking off the stimulus from the left-hand edge in response to leftward eye movements, from the right-hand edge in response to rightward eye movements, or from both edges simultaneously in response to any eye movement (see Option 1). Alternatively, the entire videoscreen may be blanked out in response to eye move- ments greater than a preset limit or in a particular direction (see Option 2). Stimulus material may be computer generated, displayed directly via a videocamera, or prerecorded on videotape. Thus, studies of laterality differences and selective attention may be freed from the constraints of the tachistoscope.

\section{EYE MOVEMENT MONITORS}

Eye movement recording methods were thoroughly reviewed by Young and Sheena (1975); more recently, electrooculographic techniques and their applications were discussed by Oster and Stern (1980) and optoelectronic devices by Haines (1980). On-line computer eye movement recorders have been reviewed by Loftus (1979) and by Rayner (1979), who also discussed their use in cognitive psychology.

Our system uses a Gulf \& Western Applied Science Laboratories (ASL) Eye-Trac Model 200 research eye movement monitor (formerly known as a Biometrics Model 200), coupled with an optional video fixation point display unit. The Model 200 measures the horizontal direction of gaze with respect to the head by utilizing the differential reflectivity of the iris and sclera. Vertical movements may, if desired, be measured by detecting changes in the reflected light between the eye itself and the lower lid, which is said to follow vertical movements of the eye quite closely (Gulf \& Western Research and Development Group, 1980). Changes in the reflected light, and hence eye movements, are sensed by a pair of silicon phototransistors operating in conjunction with a gallium arsenide modulated infrared source mounted on spectacle frames in front of each eye. The current produced by each pair of phototransistors is treated by an amplifier-demodulator to yield a single-ended, low-impedance output voltage proportional to the angular displacement of the eye. The video fixation point display option presents the subject's eye position as cross hairs or a spot, superimposed over a television image of the scene being viewed by the subject. This system is said to be capable of measuring horizontal eye movements over a range of approximately $\pm 20 \mathrm{deg}$, with a resolution of $1 \mathrm{deg}$. Horizontal resolution can be improved to a few minutes of arc with rigid head mounting, such as is achieved by a biteboard. The response time of the system can be varied with filter switches from approximately 4 to $26 \mathrm{msec}$ (Gulf \& Western Research and Development Group, 1980).

A similar system (Narco-Biosystems Model 200) was used by Rayner $(1975,1979)$ and Salthouse et al. (1981), but Rayner and his colleagues (see Pollatsek et al., 1981, Rayner, 1979; and Rayner et al., 1980, 1981) seem to have settled for a Stanford Research Institute Dual-Purkinje Eyetracker (Clark, 1975). The Dual-Purkinje Eyetracker has a frequency response of $300 \mathrm{~Hz}$ (Young \& Sheena, 1975), with a 
resolution of $10 \mathrm{~min}$ of arc, and is linear over at least $14 \mathrm{deg}$, and, when coupled with an on-line computer system, can accomplish a display change within 2$10 \mathrm{msec}$ after the termination of a saccade (Rayner et al., 1981).

\section{HEAD MOVEMENTS}

When eye movements are being monitored in order to determine or control the regions of a stimulus being fixated, it is necessary either to restrict head movements or to monitor them and then to integrate both head and eye movements to determine the exact point of regard. Even the commonly used, but very uncomfortable, biteboard (formed by getting the subject to bite into dental wax) allows some head movement. Some researchers have therefore been forced to resort to somewhat barbaric methods. Ditchburn (1973) reports that Barlow (1952) "took extreme precautions to fix the head. The subject's head rested on a stone slab let into the wall. A rigid iron frame fitted round the head and wedges were driven in on one side. The teeth were fixed by a dental impression" (p. 54)! It is therefore probably preferable to limit head movements and then to measure and integrate them with the eye movements. Various methods of doing this are reviewed by Young and Sheena (1975). The system described below incorporates a head movement transducer, the output of which is integrated with the output of the eye movement monitor.

\section{APPARATUS}

\section{Principles of Operation}

A video signal for figures, words, or passages of text may be presented on a video monitor as a controlled-width window (the window mode) in which areas outside the window boundaries are blanked; alternatively, the inverse may be generated, whereby the central window is blanked (the masked mode) and the outer window area displays text, etc. The width of the window or mask is achieved by varying the pulse length of a monostable multivibrator that has been triggered by an analog comparator. The comparator compares a sawtooth waveform (integrated, computer-generated, horizontalvertical, video-sync pulses) with the summed dc levels obtained from an ASL Model 200 Eye-Trac system and an in-house head movement circuit (see below). The net effect is that a mask or window will track across the video monitor in proportion to the amount of head and/or eye movement. A white line may be generated within the mask to serve as a fixation stimulus. This line will then follow the subject's eye movements.
Block diagrams are shown in Figure 1a for the complete system and in Figure $1 \mathrm{~b}$ for the various circuits that make up the control unit for the system. As presently used by the authors, the system uses a National Semiconductor RMC 80/14 microcomputer together with a BLC 8229 video board to generate the video signal, which is simultaneously displayed on the video fixation point display monitor and the subject's monitor. With a few minor adjustments to accommodate different horizontal scan frequencies, the system can be used with other microcomputers, videotape recorders, or a videocamera. Likewise the system can accommodate alternative eye movement monitoring devices with dc output.

\section{The Head Movement System}

This system (see Figure 2) consists of a fixed light source, two cadmium sulphide photoconductive cells (the head movement transducer) and their respective voltage followers, a differential operational amplifier, a nulling amplifier, and an analog meter. The transducer is mounted into a light-tight housing that consists of a central fixed incandescent light and two photocells (RPY 85) mounted onto a slider mechanism that is attached to the Eye-Trac headband by a semiflexible coupling (e.g., stiff polythene tubing). The signal from each photocell is fed via a voltage follower (IC-1 and IC-2) into a differential amplifier (IC-3), which provides an output voltage proportional to the horizontal linear displacement of the subject's head. The nulling amplifier (IC-4) is used by the operator to accommodate subject head movement that has occurred during intertrial rest periods. Head movements can be observed as a deflection on the analog meter. This system has no inherent advantage over commercially available linear motion transducers, but it achieves linearity over the range of movement allowed (i.e., $10-\mathrm{mm}$ displacement to left or right) and is therefore a cheaper alternative. Greater freedom of movement would require a more sophisticated system to measure and integrate angular rotation of the head.

\section{Eye-Trac and Head Movement Circuit}

The dc potential derived from the ASL Eye-Trac unit is summed (see Figure 3) with the output of the head movement system by a unity gain inverting amplifier (IC-5). This output is inverted by another unity gain amplifier (IC-6), and the outputs of each of these amplifiers can be switched (SW-1), thus providing the operator with an optional facility whereby the window or mask moves in the same direction as the subject's head or eye movement ("with") or in the opposite direction ("opposite"). The switched output is then amplified by a noninverting amplifier (IC-7). The combined head movement and Eye-Trac signal is fed to the inverting input of a comparator 
(a)

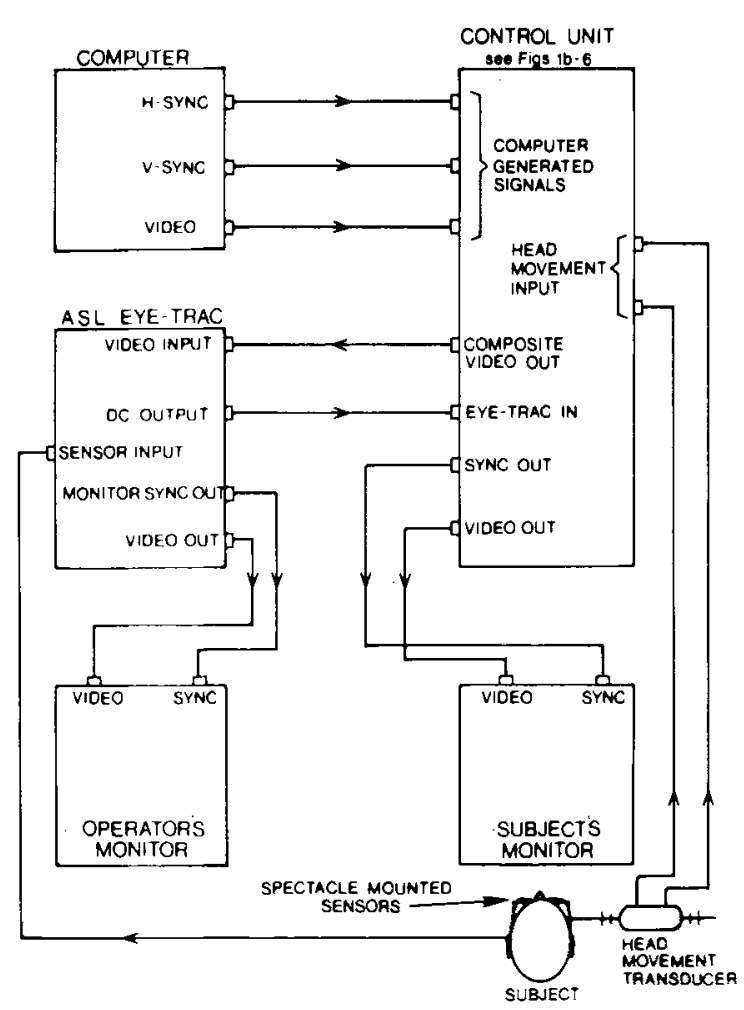

(b)

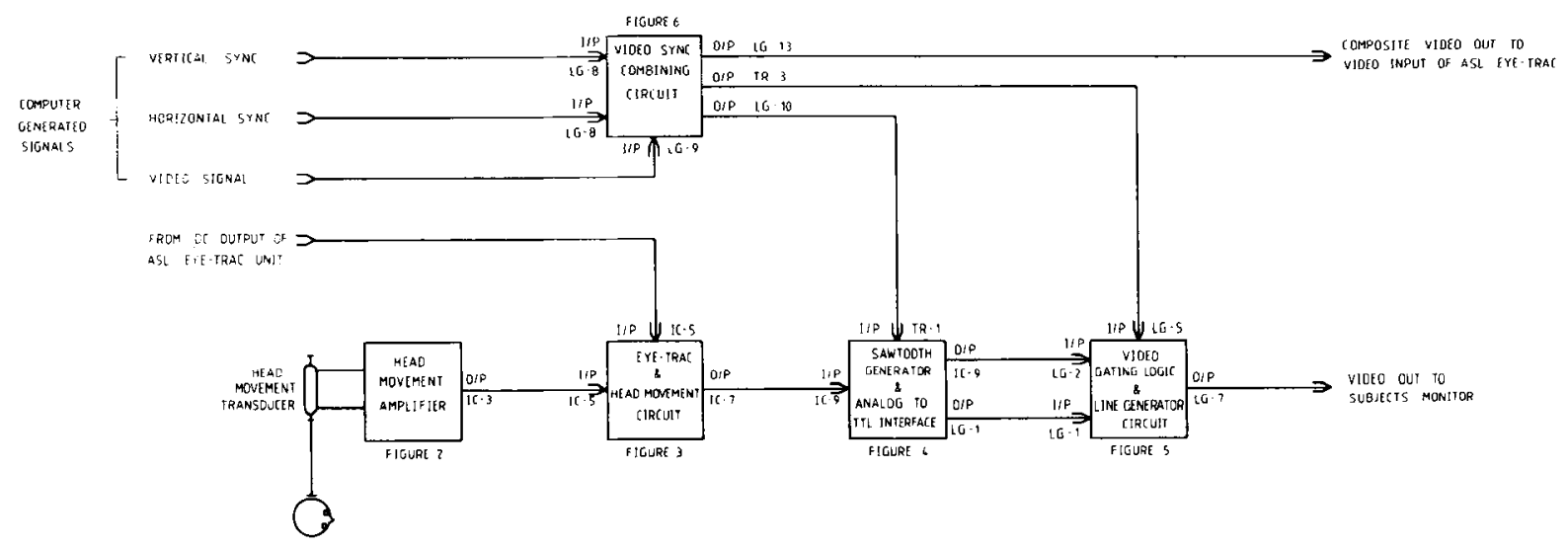

Figure 1. Block diagrams of (a) the comple te visual display system, and (b) the various circuits making up the control unit for the visual display system.

(IC-9); this signal determines the trigger level of the comparator.

\section{Sawtooth Generator and Analog to TTL Interface Circuit}

This circuit (see Figure 4) consists of a transistor level translator, 700-nanosec monostable, a fast integrator, and a comparator. The level translater am-

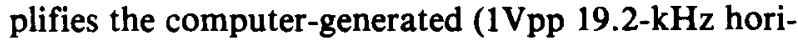
zontal video-sync pulses to a level suitable for triggering TTL. The monostable (LG-1) is triggered via each pulse, produces a 700-nanosec negative-going pulse that, via a transistor interface (TR-2) and a field effect transistor (FT-1), discharges the $470 \mathrm{pF}$ capacitor (C-1) in the integrating amplifier (IC-8).
This amplifier, in conjunction with the horizontal video-sync pulses, is the sawtooth generator. The sawtooth output is fed into the noninverting input of a comparator (IC-9); a 1-megohm resistor is used in the feedback loop to provide hysteresis. When the sawtooth voltage equals or is greater than the dc voltage of the Eye-Trac/head movement amplifier (IC-7), the comparator changes state.

\section{Video Gating Logic and Line Generator}

The negative edge of the comparator (IC-9) triggers the mask/window width monostable multivibrator (LG-2; see Figure 5) producing a pulse the duration of which can be varied by the operator. This monostable is retriggered via the " $Q$ " output 


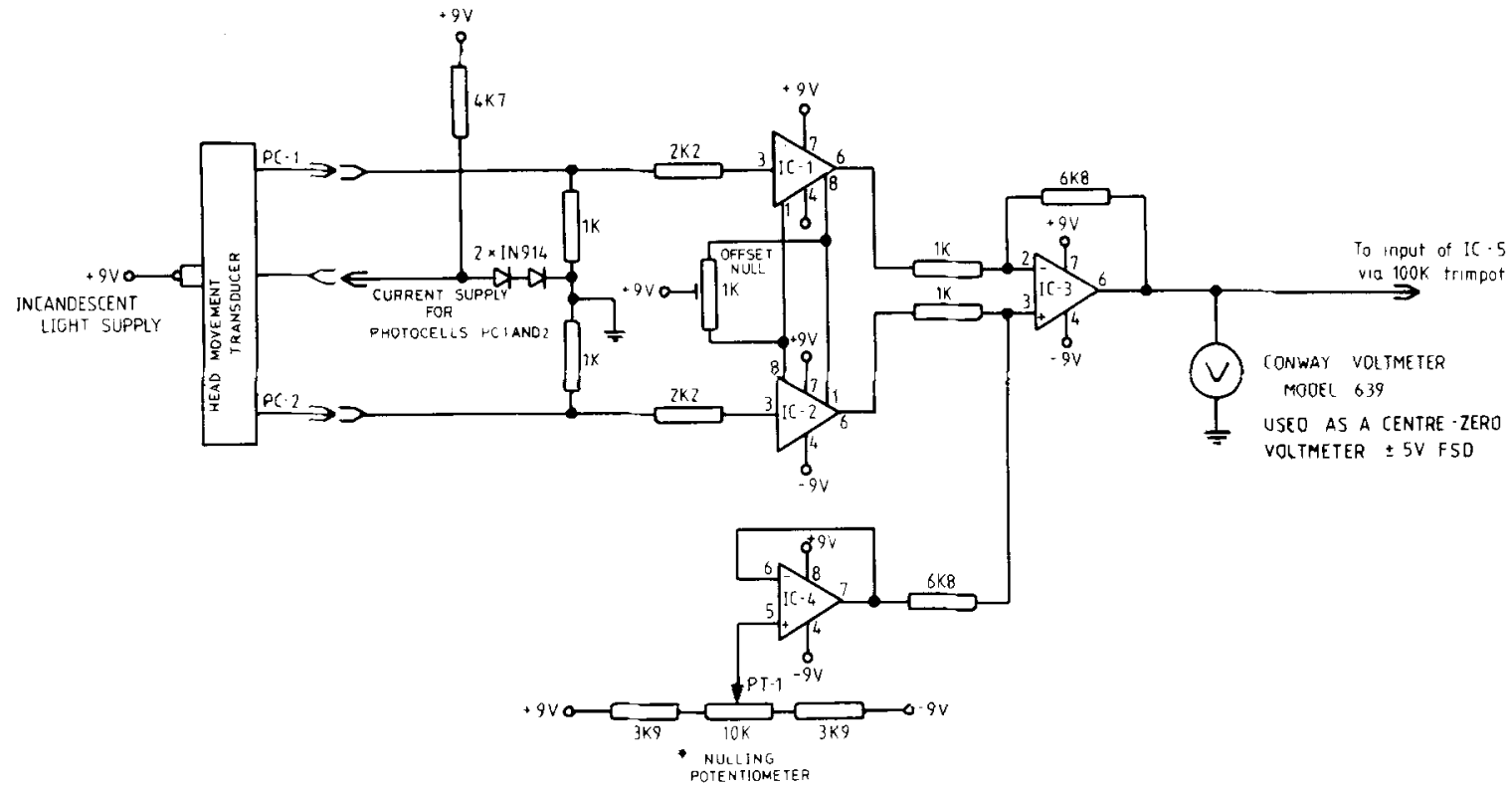

SEMICONOUCTOR DEVICES

* operator control to offeset

INTER - TRIAL SUBJECT HEAD

MOVEMENT AS OBSERVID ON THE

CONWAY VOLTMETER

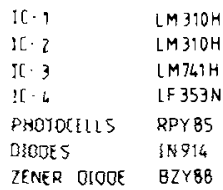

Figure 2. Circuit diagram for the head movement system.

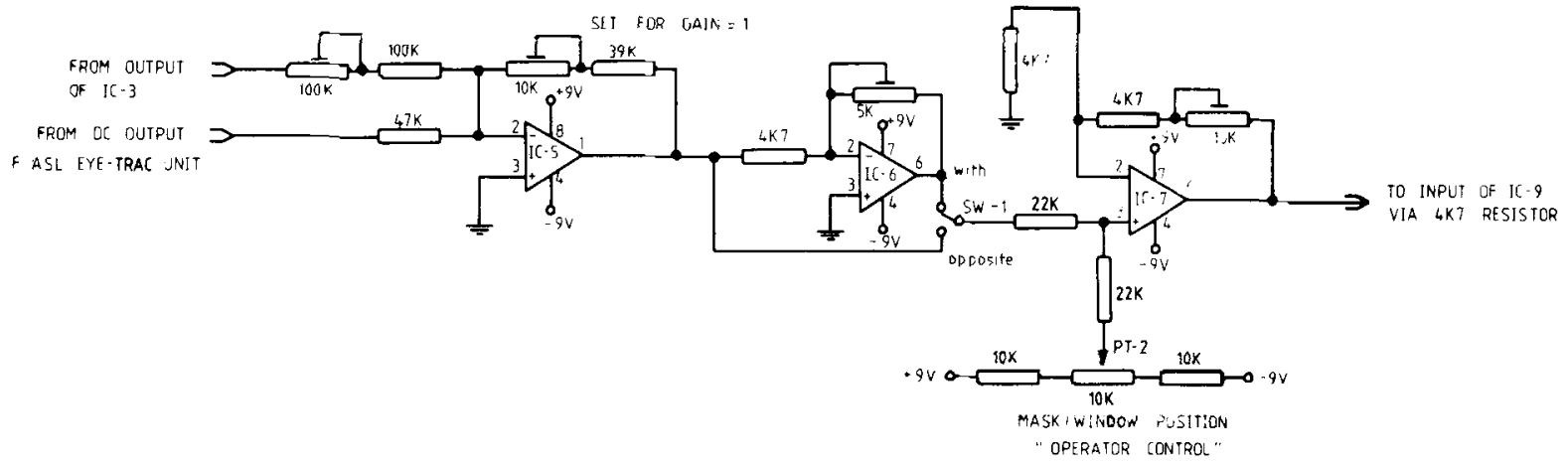

\begin{tabular}{|c|c|}
\hline SEMIEDNDUC IDR & DEVIES \\
\hline$\pi c \cdot 5$ & $1+353 \mathrm{~N}$ \\
\hline KC. & $L M+41 \mathrm{~N}$ \\
\hline $16 \cdot 1$ & LMTL1N \\
\hline DTOOES & IN914 \\
\hline ZENER OIODE & $B 2 Y 8 B$ \\
\hline
\end{tabular}

Figure 3. Dlagram of the circuit for summing the outputs of the Eye-Trac and head movement aystems. 


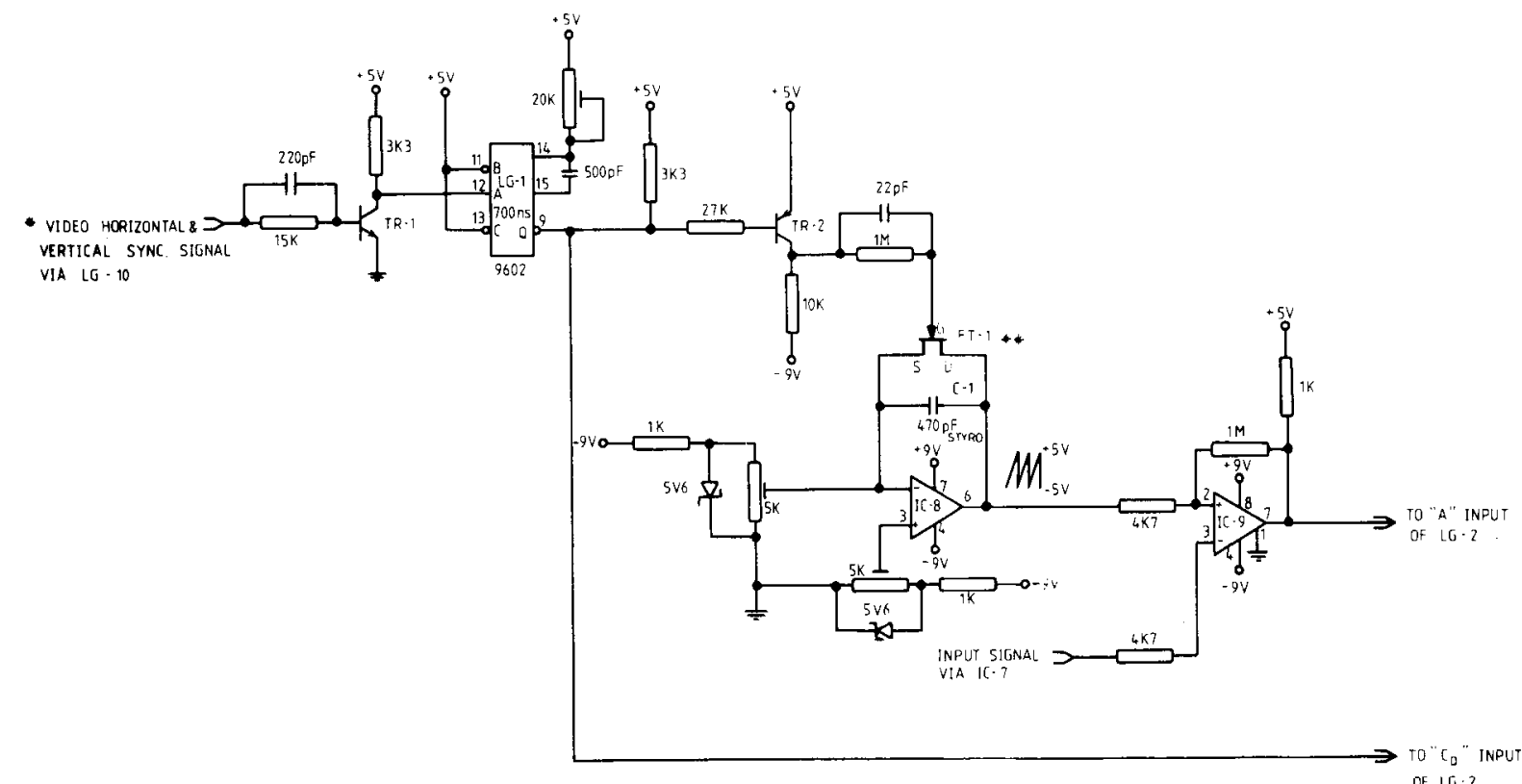

- note the computer -generated vertical syne pulse thOUGH integrated BY IC-8 IS FunCtIONALLY

SEMICONDUCTOR DEVICES

REDUNDANT IN TH!S CIRCUIT.

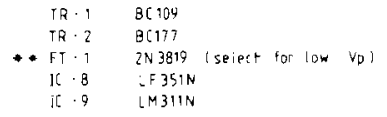

Figure 4. Diagram of the snwtooth generator and analog to TTL interface clrcult.

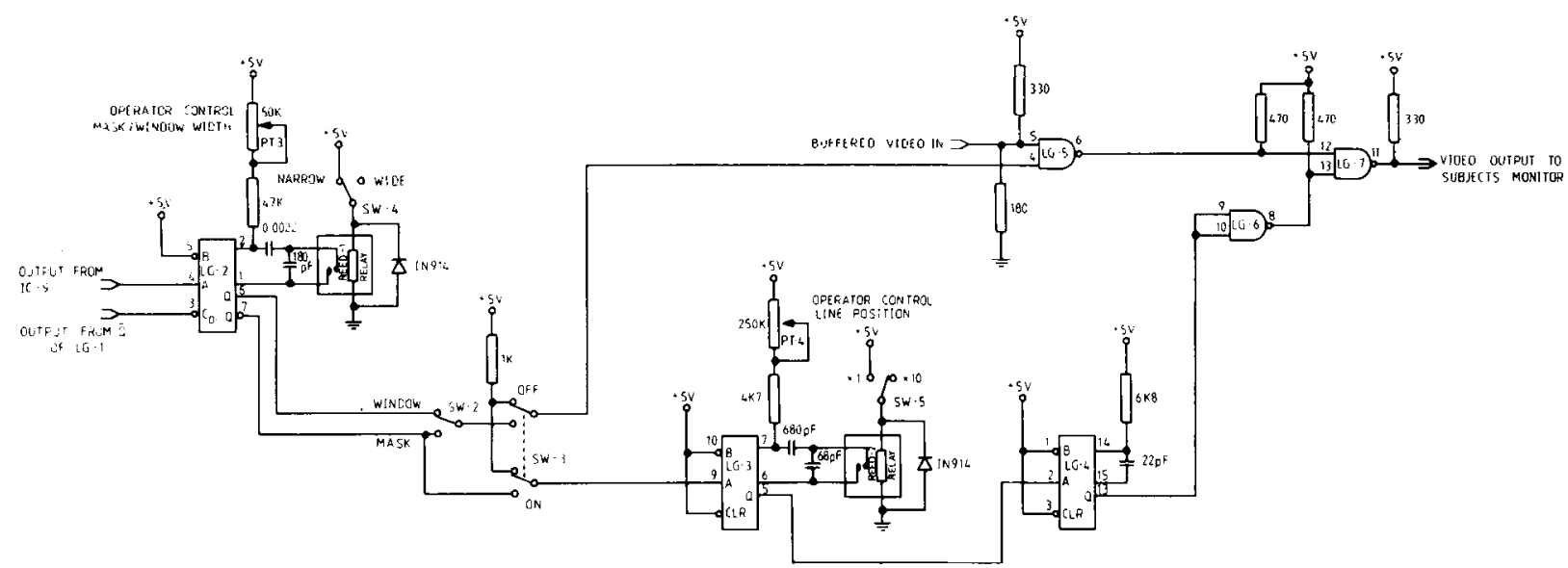

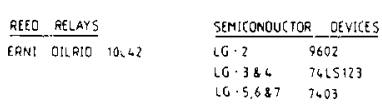

Figare 5. Circult diagram for the video gating logic and line generator. 
of the 700-nanosec monostable (LG-1), thus ensuring that the video logic control circuitry is synchronized to the computer-generated horizontal video pulses.

The window/mask monostable (LG-2) can provide two ranges of programmable pulse widths via SW-4. This feature allows the operator to present a mask or window from less than 1 to 69 characters (i.e., the full screen) wide. This is achieved by manually switching the $180 \mathrm{pF}$ capacitor (C-2) out of the monostable's resistor/capacitor timing network via reed relay $R L Y-1$. The range of window/blanking widths required in the research parameters could not be achieved using a single capacitor timing element. The " $Q$ " and " $Q$ " (NOT $Q$ ) outputs of LG-7 (the pulses that determine the window or mask width) can be switched by the operator via switch SW-2. Thus, when SW-3 is on and SW-2 is selected for window mode, the " $Q$ " output of LG-2 is fed to one input of a nand gate (LG-5). This pulse then acts as the gating pulse for the "buffered video in" signal. The output of LG-5 is fed into one input of nand gate LG-7, and this enables the video signal to the subject's monitor.

The other input of LG-7 is controlled via the linegenerating circuit (see Figure 5) consisting of LG-3, LG-4, and LG-6. The negative transition ( $Q$ output) of monostable LG-2 triggers the monostable LG-3, the pulse width of which is user programmable via a $250 \mathrm{~K}$ potentiometer PT 4 . The monostable LG-4, with its pulse width fixed at 70 nanosec, is triggered via the negative edge of the " $Q$ " output of LG-3.
Thus, the 70-nanosec pulse can be effectively moved within the window or mask by the operator, and its relationship within the confines of the mask or window is maintained for both head and eye movement of the subject. Nand gate LG-6 inverts and buffers the positive-going pulse derived from LG-4, and this negative-going pulse inhibits 70 nanosec of video information being presented to the subject's monitor via nand gate LG-7. This 70-nanosec inhibition period generates the vertical line upon the subject's monitor

\section{Video/sync combining circuit}

The video-sync combining circuit (see Figure 6) distributes the computer-generated video signal, and the horizontal and vertical sync pulses, to the EyeTrac unit, to the sawtooth generator, and to the video gating logic circuit. The horizontal and vertical sync pulses are "NOR-ed" and buffered by LG-8 and LG-10 and then fed to TR-1 of the sawtooth generator circuit (see Figure 4). The video signal and the horizontal/vertical sync pulses are buffered by LG-9, LG-12, and LG-11. These signals are then resistively combined and fed via emitter follower (TR-3) to the video input of the Eye-Trac unit. The video signal is further buffered by LG-13 and then fed to LG-5 of the video gating logic circuit (see Figure 5).

\section{Options}

A number of options are being developed; these will permit: (1) masking off a stimulus from both

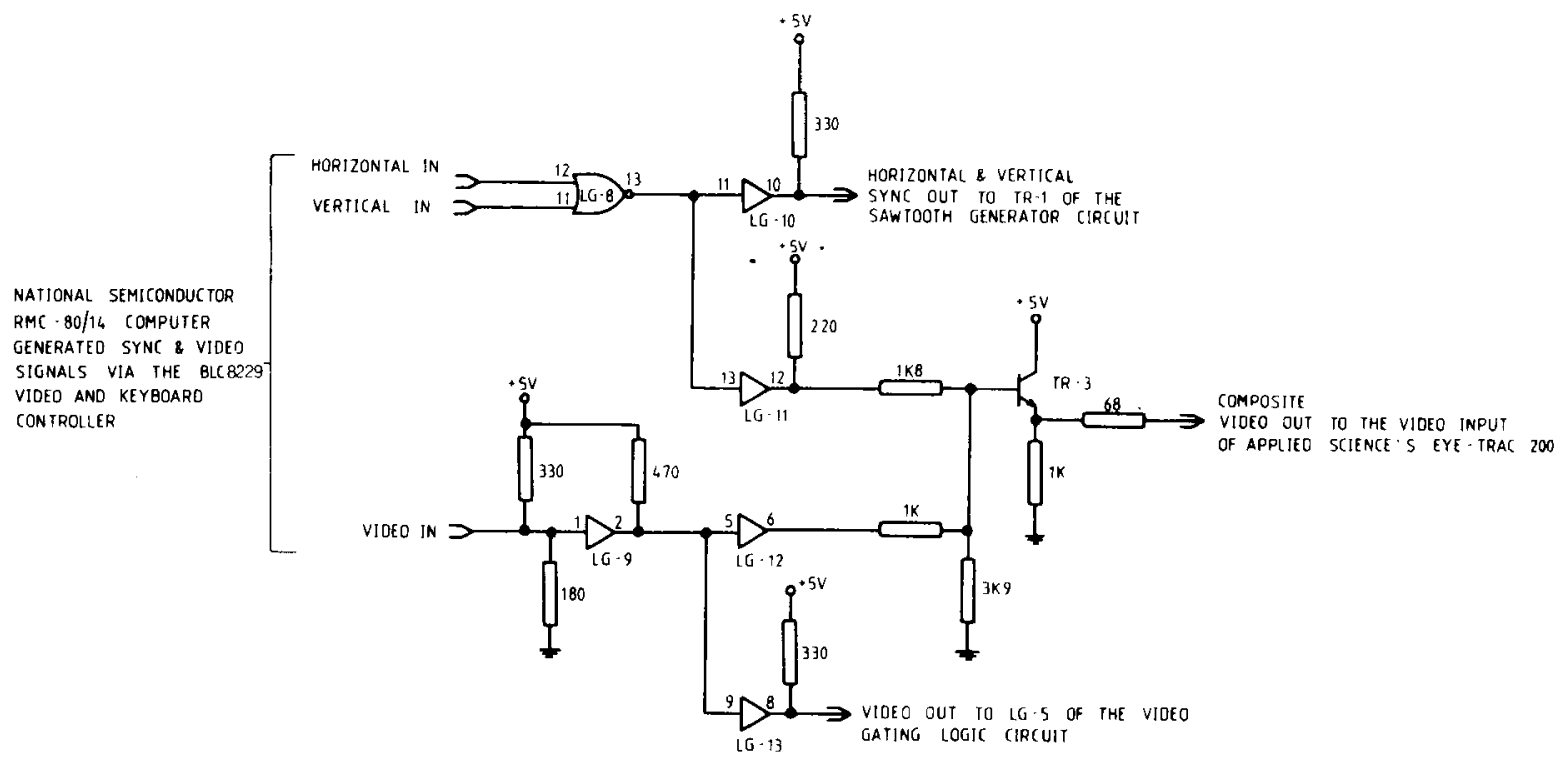

ALL INPUTS AND OUTPUTS ARE TERMINATED FOR $75 \Omega$

\begin{tabular}{|c|c|}
\hline SEMICONDUC TOR & DEVICES \\
\hline $\begin{array}{l}\text { LC }-8 \\
\text { LG }-9 \rightarrow 13\end{array}$ & $\begin{array}{l}7402 \\
7407\end{array}$ \\
\hline TR-3 & $2 N 3643$ \\
\hline
\end{tabular}

Figure 6. Dlagram of the video-aync combining circuit. 
edges simultaneously in response to any eye movement, and (2) blanking out of the entire screen in response to eye movements greater than a preset limit or in a particular direction. Details of the modifications required for these options are available from the second author.

\section{Setting Up}

Before fitting the "spectacles" and adjusting the Eye-Trac sensor alignment, so that a symmetrical output is obtained for symmetrical eye movements, it is important to adjust the system for the required mode of operation. This is achieved by setting the head transducer and the Eye-Trac meters to zero and then switching in the mask or window (SW-2; Figure 5) and adjusting its position via the potentiometer PT-2 (Figure 3), width via SW-4 and potentiometer PT-3 (Figure 5), and direction of movement (SW-1; Figure 3). This ensures that the mask or window will be correctly positioned when the sensors have been adjusted to give a symmetrical response (see Gulf \& Western Research and Development Group, 1980, pp. 2-9 to 2-12). It is also important that, before the sensors are adjusted, the subject's head is firmly "secured" and his or her head and eyes are lined up with the center of the videoscreen. In our laboratory, this is achieved by tilting the subject back about 60 deg in a dental chair and attaching braces between the chair's adjustable headrest and the side of the headband (adapted from a welding mask) to which the Eye-Trac "spectacles" and sensors are attached. This has proved to provide sufficient restraint to head movement without causing discomfort.

Once the Eye-Trac has been properly set up and adjusted, according to the manual (Gulf \& Western Research and Development Group, 1980), the EyeTrac meter should give a symmetrical deflection to the left or the right of zero when the subject fixates points an equal distance to the left or the right of the central fixation point. A special 9-point, computergenerated, callibration matrix is used for this purpose (see Gulf \& Western Research and Development Group, 1980, p. 2-10). When this initial setting up has been achieved, further adjustments are made, using the horizontal and vertical ZERO, GAIN, and GAIN LINEARITY controls on the front panel of the Eye-Trac, so that the cross hairs on the experimenter's monitor coincide with the point that the subject was instructed to fixate.

The complete system can then be checked by displaying a horizontal line of numbers across the screen. The subject is instructed to fixate the middle number, and the mask position is adjusted so that it is, for example, one character to the left or the right of the fixation character. If the subject is then instructed to fixate on a specific number, anywhere across the screen, the edge of the mask should retain the same position relative to this new fixation point (i.e., one character to the left or the right). With practice and careful adjustment, this situation is readily achieved.

\section{CHARACTERISTICS OF THE SYSTEM}

\section{Visual Display}

The display area currently employed is $235 \mathrm{~mm}$ wide and $175 \mathrm{~mm}$ high. At a viewing distance of $650 \mathrm{~mm}$, this subtends a visual angle of $20.49 \times$ $15.33 \mathrm{deg}$. Alphanumeric characters are $2.5 \times 4 \mathrm{~mm}$ (i.e., they subtend a visual angle of $.22 \times .35 \mathrm{deg}$ ). A maximum of 25 lines of 69 characters can be generated and displayed.

\section{Linearity}

An output of $55.2 \mathrm{mV}$ is required from the EyeTrac Model 200 to move the mask 1 character width. When a Data Precision 8100 voltage standard was used to simulate this output, the system was shown to be linear over 20 characters in either direction, with a 6-mV offset required to move the mask 30 characters. The system is thus linear within the range likely to be employed in most laterality studies.

\section{Response Time}

The sampling rate of the ASL Eye-Trac Model 200 is continuous, and response time can (according to Gulf \& Western Research and Development Group, 1980) be switched between approximately 4 and $26 \mathrm{msec}$. The shorter response time should be employed. Careful measurement has shown that, in this mode, the response time is $8.5 \mathrm{msec}$ ( $26 \mathrm{msec}$ with the filter switched in). The control unit (Figure 1a) adds a further 28 microsec. Thus, the system responds to an eye movement in less than $9 \mathrm{msec}$. At any point on the screen, the mask will be repositioned in response to the output of the control system once every $20 \mathrm{msec}$ (i.e., on each new raster scan). This 20 -msec "delay" is not a problem, because the points decay to $10 \%$ in 50 microsec and a forward or backward eye movement will not (unless completed within 50 microsec) result in fixation on the previously illuminated text (i.e., that put up by the last pass of the raster), and on the next pass the mask will have been repositioned.

\section{Noise Characteristics}

A series of readings of the mask position recorded with an artificial eye (a prosthetic glass eye) mounted to allow mechanical "eye movements" showed the system to be totally free of noise over a range of eye movements greater than those anticipated in any experimental studies.

\section{Drift}

Using the artificial eye, readings were taken every $15 \mathrm{sec}$ for $30 \mathrm{~min}$ at (1) the low end of the scale (i.e., central fixation) and (2) the high ends of the scale 
(i.e., left and right fixation). The amount of drift recorded did not exceed half of a character, and for $90 \%$ of the observations was less than a quarter of a character.

\section{CONCLUSION}

The system described above should permit further investigation of the nature and extent of visual field asymmetries with a full range of verbal (letters, words, word lists, sentences, and paragraphs of text) and patterned stimuli. Alphanumeric and simple patterned stimuli can be generated by a microprocessor, and more complex stimuli can be taken directly from drawings, photographs, or even "live"' scenes via a video system. The ability to mask any part of a subject's visual field (central or peripheral, left or right) with a mask of almost infinitely variable horizontal extent permits extended viewing of such stimuli. This was not possible with tachistoscopic techniques and severely limited the material, and often the choice of subjects, that could be employed in laterality and selective-attention studies.

A series of studies in our own laboratory is proving the value of this system. In a recently completed experiment, subjects demonstrated the expected right visual field superiority when required to detect the presence of a target letter in a $3 \times 3$ matrix of letters exposed in the left or the right visual field for a range of five exposures between 50 and $800 \mathrm{msec}$. We have almost completed a second experiment involving the extended presentation of pairs of words to either visual field and requiring a decision as to whether the words rhyme or not. Pilot studies have been completed in which video recordings of biological movement represented by a dynamic point-light display (Johansson, 1975) were presented in left and right visual fields. This technique is the basis of an important new series of experiments on hemispheric functioning. These latter experiments would not have been possible without a system such as this one.

\section{REFERENCES}

Barlow, H. B. Eye movements during fixation. Journal of Physiology, 1952, 116, 290-306.

Bradshaw, J. L., \& Nettleton, N. C. Human cerebral asymmetry. Englewood Cliffs, N.J: Prentice-Hall, 1983.

Clark, M. R. A. A two-dimensional Purkinje eye tracker. Behavior Research Methods \& Instrumentation, 1975, 7, 215-219.

Dimond, S. J., Bures, J., Farrinoton, L. J., \& Brouwers, E. Y. M. The use of contact lenses for the lateralization of visual input in man. Acta Psychologica, 1975, 39, 341-349.

Dimond, S. J., \& FArrington, J. Emotional response to films shown to the right or left hemisphere of the brain measured by heart rate. Acta Psychologica, 1977, 41, 255-260.

Ditchburn, R. W. Eyemovements and visual perception. Oxford: Clarendon Press, 1973.

Ditchburn, R. W., \& Ginsborg, B. L. Vision with a stabilized retinal image. Nature, 1952, 170, 36-37.

Gulf \& Western Research and Development Group.
Model 200 eye movement monitor operator and service manual. Waltham, Mass: Author, 1980.

HaINES, J. D. Eye movement recording using optoelectronic devices. In I. Martin and P. H. Venables (Eds.), Techniques in psychophysiology. New York: Wiley, 1980.

Johansson, G. Visual motion perception. Scientific American, $1975,232(6), 76-88$.

Kinsbounne, M. The mechanism of hemispheric control of the lateral gradient of attention. In P. M. A. Rabbitt \& S. Dornic (Eds.), Attention and performance $V$. New York: Academic Press, 1975.

Lofrus, G. R. On-line eye movement recorders: The good, the bad, and the ugly. Behavior Research Methods \& Instrumentation, 1979, 11, 188-191.

Mackworth, N. H. Visual noise causes tunnel vision. Psychonomic Science, 1965, 3, 67-68.

McConkie, G. W., Zola, D., Wolverton, G. S., \& Burns, D. D. Eye movement contingent display control in studying reading. Behavior Research Methods \& Instrumentation, 1978, 10, 154-166.

Myers, J. T., \& SPERry, R. W. A simple technique for lateralizing visual input that allows prolonged viewing. Behavior Research Methods \& Instrumentation, 1982, 14, 305-308.

NeIssen, U. Cognition and reality: Principles and implications of cognitive psychology. San Francisco: Freeman, 1976.

Oster, P. J., \& Stern, J. A. Measurement of eye movement. In I. Martin and P. H. Venables (Eds.), Techniques in psychophysiology. New York: Wiley, 1980.

Pollatsek, A., Bolozky, S., Well, A. D., \& Raynen, $K$. Asymmetries in the perceptual span for Israeli readers. Brain and Language, 1981, 14, 174-180.

RAYNER, $K$. The perceptual span and peripheral cues in reading. Cognitive Psychology, 1975, 7, 65-81.

RAYNER, $K$. Eyemovements in reading and information processing. Psychological Bulletin, 1978, 85, 618-660.

RAYNER, K. Eye movements and cognitive psychology: On-line computer approaches to studying visual information processing. Behavior Research Methods \& Instrumentation, 1979, 11, 164-171.

Rayner, K., Inhoff, A. W., Morrison, R. E., Slowiaczex, M. L., \& Bertera, J. H. Masking of foveal and parafoveal vision during eye fixations in reading. Journal of Experimental Psychology: Human Perception and Performance, 1981, 7, 167-179.

Rayner, K., Werl, A. D., \& Pollatsek, A. Asymmetry of the effective visual field in reading. Perception \& Psychophysics, $1980,27,537-544$.

REDER, S. M. On-line monitoring of eye position signals in contingent and noncontingent paradigms. Behavior Research Methods \& Instrumentation, 1973, 5, 218-228.

Riggs, L. A., Ratliff, F., Connsweet, J. C., \& Connsweet, T. N. The disappearance of steadily fixated test objects. Journal of the Optical Society of America, 1953, 43, 495-501.

Salthouse, T. A., Ellis, C. L., Diener, D. C., \& Somberg, B. L. Stimulus processing during eye fixations. Journal of Experimental Psychology: Human Perception and Performance, 1981, 7, 611-623.

YounG, A. W. Methodological and theoretical bases of visual hemifield studies. In J. G. Beaumont (Ed.), Divided visual field studies of cerebral organization. New York: Academic Press, 1982.

Youna, L. R., \& Sheena, D. Survey of eye movement recording methods. Behavior Research Methods \& Instrumentation, $1975,7,397-429$.

ZAIDEL, E. A technique for presenting lateralized visual input with prolonged exposure. Vision Research, 1975, 15, 283-289.

ZAIDEL, E. Auditory vocabulary of the right hemisphere following brain bisection or hemidecortication. Cortex, 1976, 12 , 191-211.

ZaIDEL, E. Auditory language comprehension in the right hemisphere following cerebral commissurotomy and hemi- 
spherectomy: A comparison with child language and aphasia. In A. Caramazza \& E. B. Zurif (Eds.), Language acquisition and language breakdown: Parallels and divergencies. Baltimore: Johns Hopkins University Press, 1978. (a)

ZaIdes, E. Concepts of cerebral dominance in the split brain. In P. A. Buser \& A. Rougeul-Buser (Eds.), Cerebral correlates of conscious experience (Inserm Symposium No. 6). Amsterdam: Elsevier/North-Holland, 1978. (b)
Zangwill, O. L., \& Blakemore, C. Dyslexia: Reversal of eyemovements during reading. Neuropsychologia, 1972, 10, 371-373.

(Manuscript received May 13, 1983; revision accepted for publication August 12, 1983.) 